flammation, is e referred to the irritation given by the local disease to the general system, in consequence of the eympathy existing thronghout the whole. The brain is probably the medium, through which the general disorder is excited : the local disease first exciting the brain by irritation, and the brain in consequence, reacting upon the rest of the system.

It does not appear, however, to be actual inflammation that is thus excited in the brain; since the phenomena of inflammation are wanting. There is neither pain in the head, nor any material disorder in the functions of this organ. Yet it seems on some occasions to pass readily into actual inflammation of the brain, wirh all the characters of this affection, in the form of either phrenitis, or idiopathic fever, as it is called. This is particularly apt to occur, when the skin is extensively inflamed; as in erysipelas; but occasionally also in the course of inflammation in other organs.

The pyrexia or febrile state attending infiammation, appears to be something more than simple increase of action in the general vascular system; since it is marked by disorder in all the finctions. Both the appearances and feel of the skin are altered,especially that which covers the npper surface of the tongue; the various secretions and excretions are disordered; the general feelings, bodily and mental, are disturbed; the rest is broken, and sleep rendered unnatural. The excitement produced by the warm bath, by active exercise, or even a moderate employment of stimulating food and drinks, has little or no resemblance to the real tebrile state.

In a word, the phenomena of inflammation taken together, show the part to have all its vital properties increased: wamely, its sensibility, its mobility, its vascular action, and all the ordinary conseqnences of this, as tendency to growth or enlargement, and to the production of new fluids. So far then inflammation is a state of increased action; but the action is at the same time unnatural, or different from that of health. But with the nature of this change, we are totally unacquainted. The theory of inflammation, therefore, is imperfect; and in the treatment of it, we are obliged to call to onr aid the lights of experience and observation, having no adequate rational guide to direct us, that is, as derived from the known nature of the disease.

\section{SKETCHES Of THE SURGICAL PROFESSION IN IRELAND.}

\author{
No. IX.
}

MR. CARMICHAEL.

THERE are certain impressions which, though perhaps of little importance in themselves, the mind retains throngh every vicissitude with a singular tenacity. Such, in general, are those produced early in life by the observation of men pointed out to our notice for some personal pecu. liarities orintellectual endowments. Com. pared with what may well be called these proof impressions of the memory, struck off, as if, in the propitions excitement of the occasion that gave them birth, all subsequent recollections of the same objects are feeble and evanescent. Never did the learning of the Royal College of Surgeons in Ireland appear so awfuily classical to my imagination since $\mathrm{Mr}$. Hewson confronted me in a dialogue of Lucian, or Mr. Colles seem so sublimel physiological as when I first heard him hold forth on the freezing of a rabbit's ear. It may be owing to some influence of this kind, which original associations exercise over the mind, that $I$ have chosen, almost instinctively, to describe the subject of this essay from a likeness taken at a very interesting crisis of my existence, and which, from the circnmstances of the event, has bid defiance to all the casualties of obliviscence.

It is now some years ago since, walking in company with a friend into the Westmoreland Lock Hospital of Dublin, elate with all that consequence which an indenture just signed, and the anticipation of fame and fortune usually inspire in the breast of a surgeon's apprentice, our conversation tarned upon the disease to which that once celebrated institution was dedicated, the professional characters who superintended its concerns, and the best means of converting its then numerous advantages to a profitable account. As eager to learn the particulars of an establishment, in which no small portion of my small capital had been vested, as my friend was willing to communicate the required information, we passed on through several apartments, observing as I went along, with qualmish curiosity, the frightful effects of the "veneris monumenta nefands" that appeared on every side, but listening all the 
the with respectful attention, notwith-|battery of mental expression-the oval standing the delicate state of my stomach, disk of the countenance of an uniform to one of those parental admonitions tint, surrounded by a continuous fring, which the experience of a senior pupil of dark hair and whiskers-formed a qualifies him to inflict on his younger combination of features which awed me, acquaintance, about to commence the im- I must confess, into a state of feeling portant duties of folding pledgets of lint bordering on fear. There was something and smearing old linen with varions un- so repulsive and intimidating about him guents. Entering another of these re- that $I$ could not admit the truth of the ceptacles of female depravity, where panegyrics so lavishingly bestowed one every pallet exhibited some sad memo- him by my friend withont painful relncrial of the truth of "f frailty, thy name is woman," my companion stopped, and pointing to a man at the end of the room, "there," said he, " is a gentleman who has lately published an excellent treatise on syphilis, from the pernsal of which you will derive much useful instruction," accompanying the recommendation of the work with a high-wrought euloginm on the writer. Fixing my eyes on the revealed author with all that intensity of mute anazement excited by such a character as had been just described to me, in the youthful spectator, I endeavoured to discover in his countenance some manifestations of that superiority conceded to him by my admiring cicerone, "but the only conclusion I could come to was, that he seemed a very strange-looking gentleman in black. He might, at the time, have been probably enforcing the truth of his favourite syphilitic doctrine-cevery sore has its peculiar secondary symptoms,"-to a crowd of satellites, amongst whom he looked like an embryo thunder cloud, amidst its less dusky companions, gathering round the nucleus of the storm. Without being at all singled out as a subject of remark, or raised to the enviable dignity of the "digito monstrari," Nature, in her unlimited powers of diversifying " the human face divine," had bestowed on him quite a sufficiency of her attention in this respect to attract the gaze of one who had never even devoted an hour to the pages of Lavater. In so obvious a degree, indeed, was this the case, that had I met him amongst the gay illusions of the fancy ball, instead of the sad realities of a hospital, I night have mistaken his face for a mask, executed after a model of a North American Indian, in which the artist had essayed all his mimic powers to represent the bold, audacious bearing of the ruthless master of the tomahawk. The martial flexure of his nose-the determination seated on the closely-approximated liys-the halo of defiance encircling his ample brows--the mixture, shatl I say, of mischief and design lurking in the corner of an eye half concealed by its length of lashes, which reemed to act as the conductors of this tance; nor could I readily believe, that a man of so formidable an aspect could descend to trifle in soft dalliance even with the sangninary Mnse of Medicine, or that such muscularity of members as he exhibited, could be thrown away on the management of so insignificant a weapon as the pen. Hercules and the distaff scarcely presented an union of contradictions more incongruous than this gentleman toying with a feather, which, as Crayon well observes, would be more in character if placed in his head than held in his hand. This stiffness of manner appeared the very opposite to that flexibility of mind indicated in his compositions, while his lock of hanghty abstraction was at varianec with the habits of minute observation testified in his works.

It is time, however, to acknowledge, that I was seldom more deceived, or my faith in Lavater brought to solow an ebb, as by a subsequent experience of the subject of the preceding remarks. Scared by the lion's skin, I should not have forgotten that it is sometimes worn by the most generous animals, as the tenderest fruits are often protected by the roughest rind. My pleasure was, therefore, equal to my surprize, when I afterwards discovered that his glances did not possess a pet $i$ fying quality; that mankind were not really suspended in contempt from the curvature of his nose; that he might actually open his clinched lips without stunning me by the thunders of his voice; and that the free exercise of his limbs was abrolutely compatible with my safety ; facts of which, at first, I entertained the most serious apprehensions ; in short, all my fears, doubts, and dislikes were soon dissipated, as I am sure any prejudicial ideds that might have been excited by the foregoing innocuous attempts at de. scription will be cancelled, by the name of Carmichael-a name which, to all those acquainted with the person whom it re. presents, is synonymous with many excellent qualities of the head and heart.

Duly impressed, however, at my first visit to the Lock, with the great importance of chancres, buboes, phagedenic ulcers, black washes, blue pills, Mr. Car- 
michael's physiognomy, and many other things equally appalling, I could not help bestowing a portion of my attention on the appearance of the society which filled this depot of misery, for of all the spectacles I ever witnessed, this struck me as the inost extraordinary. Whatever of visible effects the combined agency of passion and pain can produce on the human countenance, were here depicted in all the horror of reality and contrast. The reckless indifference of some-the heartbroken looks of others-the sted fast stare of confirmed guilt-the irresolute glances of virtue, still unsubdued-the composed resignation of penitence, the demoniacal abstraction of stieidal meditation-the healthless blush of hectic flashing across some pallid conntenance, as if the vital current had rushed back to the bloodless cheeks of a corse-the white film mantling over some sunken eye, about to close for ever-the convulsive grasp of the hands, still clasped in the attitude of prayer, appeared in all the sad variety of woe on one side, while the hysteric laugh, the song of madness, and the exclamations of despair, resounded in my ear on the other, and without the slightest pretension to sentimentality, this unnatural medley of images, and strange confusion of sounds, realising more than the allegory of "Sin and Death," affected me even to pain. Such scenes did the female department of the Lock occasionally present; and as $I$ am on the moral picturesque of that institution, it may not be considered foreign to my objects to contrast its former with present state, as it has, since this period, undergone an entire revolution in its in. ternal arrangements.

In no other country was there an establishment of greater extent devoted to the treatment of syphilis than the Dublin Lock. Three hundred beds were the amount of accommodation-the venereal disease and poverty the cheap prices of admission. The institution, at that time, was the great resort of the surgical pupils of Dublin-it is now without a single stu. dent in its wards; it was then the theatre of Mr. Carmichael's indefatigable ndustry, and of his numerous and able coIdjutors-it is now the deserted domiion of Mr. Henthorne, Tom Egan, and tupidity; it was then managed, at least, y men in their senses-it is needless to eek a better counterpoise for the antihesis than to say, it is now in the hands f the "Saints." As a charitable instintion, half its objects have been sacriced by the exclusion of males, who are ow not permitted to profare the sancty of a mercurial atmosphere by their presence, while the increased facility for receiving females holds out a sort of premium on prostitution. As a school of surgical instruction, all its advantages have been completely destroyed by exclnding pupils, and reducing the number of surgeons from six to two, who certainly, at present, are not a " host in themselves." To be hrief, it was once an establishment of great public utility - the source of health and information to thotsands; it is now a sort of haram of penitent prostitntes, training up " in the ways of the Lord," and of Paulus Emilius Singer. To Mr. Carmichael's experiments and excellent lectures, has succeeded an "Avatar" of tracts, Bibles, and all the other unavailing agents of moral regeneration employed in modern times. The treatment of the patients received into this manufactory of Magdalens, is as fantastic as the opinions of their medical attendants are eccentric; every patient, on her admission, being put on a course of mercury and the Bible, and having spit her pint a-day, and perused her diurnal portion of chapters, she has a choice of stitching " plain or fancy work" in the Dorset Asylum, or go out to " catch cold" once more in Sackvillestreet. Should she succeed in her mission after infection, she is indulged with a second admission; but should she break her vows of chastity a third time, her head is shaved in pnnishment of her obstinacy, and she is handed over to the " powers of darkness" to pursue her avocations under the "false pretences" of a wig, never again to be admitted into the sanctuary of the Lock. Thus by borrowed curls, and a new name, do these followers of the ir cyprian progenitors, defeat the " wisdom of the wise," and get in and ont of the hospital as often as they have a necessity.

To effectuate this ludicrous plan of ar. resting vice at its origin, one of the finest establishments of the kind in the empire has fallen a victim! There were certainly some moral abuses at one time in the institution, which demanded correction, for it became necessary. in consequence of an open commnnication between the male and female wards, to keep Venus and Cupid at arm's, length by placing military centinels in the passages, but it was soon found that these true disciples of Mars, like him, were canght too in the Vulcanian net (was Mr. Crampton's sublime invention of the " net" founded on this mythological fable?) with some noseless beauty, redolent of œzena and blue pill. A classical barrier of brick and mortar was next interposed, as a substitute for the frail defence of flesh, and the lovere 
of the Lock left to murmnr their assigna- - of a book is not after all a matter of such tions through a partition without a chink. great difficulty. What operation, for inYet this perfect state of separation would stance, plan of treatment, or even prinnot satisfy the suspicions of the Saints, ciple in the practice of surgery, which who were, it seems, determined to rule might not be speciously altered or entirewithout a rival in this grand refugium ly superseded by a man of cleverness and peccatorum, which they have now entirely tact? Then in medicine every person in their possession. Leaving them then, knows that the same effects may often be for the present, in the undisturbed enjoyment of the ruin of a fine establishment, a theme of a more agreeable nature throws its refreshing shadow between us and these tinkers of the broken chinaware of female virtue, who have succeeded in propagating a vice just in proportion as they have lessened the risks attendant on its commission. So much for the moral effects of a hospital theocracy.

If it be true, as it has been somewhere asserted, that the life of an author is best studied in his works, Ireland has as yet produced no man connected with the profession of surgery, upon whom such an experiment might be made with so much propriety as on Mr. Carmichael, whose history is intimately entwined with his books. In their ingenuity, adeptation to profitable purposes, and aptitude of subject to catch the aura populuris, may be detected, some at least of the causes of his advancement in the profession. All, however, who write upon cancer, scrofula, syphilis, and other subjects of the same class, are not subject to the imputation of acting on the well known gullibility of the public, nor can it be supposed that Mr. Carmichael conld have done so. I mean merely to state a fact without the involution of a motive. He has not, however, escaped such suspicions; nor, indeed, is this at all to be wondered at, since the daily multiplication of medical books has universally given rise to an - opinion, that their anthors are solely inflienced by selfish views. On this head the public is not much in error, for not perhaps so much as one volume of sterfing merit, or one, to use the langnage of the green room, which " will keep the stage," appears amongst the some hundreds that annually issue from the press. This rapid production of books is ob. viously the result of an established law in the medical profession, that no man ever yet has made a first rate improvement, $0:$ discovery in the art, who has not been rewarded by the public. So certain of pperation is this principle, that even its abuses have produced successful results, as the fortunes accumulated by varions pretenders to superior knowledge sufficisntly demonstrate. The facility of mak ing such experiments of imposition, has tempted thousands, and will tempt as many more to the trial, for the compiling produced by the most opposite means ; that to the diversity of these means there is scarcely a limitation; and that so long as this book-making susceptibility of the science continues, so long shall we be overrun by tomes on the bind, perhaps, of a slip of wire, or the fortuitous results of a drug. In this index indicatorius of medical literature have some of Mr. Carmichael's works been included, and certainly his first essay on cancer, from the boldness of its pretension, had rather a suspicious appearance of coming into the world with the "original sin" of a bookmaking parent on its back. The secret of "guilty or not guilty," must to be sure rest with Mr. Carmichael, but it is more probable that he was sincere in his professions of the efficacy of iron in the cure of cancer, or intended his treatise to be considered as an allegory, after the manner of the rust of the Telephean sword. It is at all events a production of singular speciousness, and if $\mathrm{Mr}$. Carmichael did not succeed in making good the discovery of a specific, his profits were not in the least affected by the failure, as every old dowager afflicted with cancer, in her flight to the doctors of London and Paris, stopped on the way to pay tribute to the Baron Storck of Dublin. The leading propositions put forward in this very elaborate performance are, the vitality of cancer as an animal fungus, and its de. struction by various preparations of iron. Both these propositions are supported thronghout in the first style of hypothesis and ingenuity. By the assistance of analogy, simile, and supposition, the architect has succeeded in the construction of a fairy labyrinth, in the beautiful intricacies of which reason loses its way, and, like virtue in the temple of pleasure, is almost deprived of the powers of self-extrication. It would be superfinons to enter on a formal refutation of doctrines which have refuted themselves, or to ca?vass the efficacy of a medicine which time has deprived of its salutary propertiesthings which their anthor, at present, only regards with a smile. Nothing, indeed, is easier, in competent hands, than to raise one of those filigree works of the imagination, by a happy selection of materials and a judicious disposition of the parts. The bolder and more daring the design, the greater the chance of success, it be- 
ing a curious anomaly in our nature to believe that pretension is synonymons with desert; as when a giant tells us in a placard that he is full eight feet in height, we immediately strike a standard of our own, by taking off an inch or two from the wonder, and give him credit for being at all events a very tall man. So with the doctor who professes to cure the " incurable," we make a little allowance for exaggeration, and swallow the bait, though we suspect the hook. Nothing can be farther from my intention, than to insinuate that Mr. Carmichael had in view these frailties of onr nature in the composition of his work, which I am rather inclined to attribute to a fertile imagination, and an ardent desire to benefit mankind, than to motives which actuate only the vilest quacks.

Having established a sort of property in fee in the breasts of his fair countrywomen by his treatise on Cancer, $\mathrm{Mr}$. Carmichael next converted the nursery, that doctorial potage, into a very lucrative freehold, by the publication of an essay on Scrofula, dedicated in " high heroic prose" to Mr. Abernethy, with whom he contends the discovery of the chylopoietic chimera. Giving Mr. Carmichael full credit for his assertions, it is somewhat strange that so vast a secret should have so long remained confined in the privacy of his own breast, and that so long a period as four years should have been permitted to elapse between the publication of his claims, and the full establishment of Mr. Abernethy's, withont any attempt being made to vindicate a priority of right to the miracles of the bine pill. It is possible that heaven might have revealed to him this grand arcanum before it was dreamed of by the Chancery hero of defeat, but it must be confessed, that it is not according to the dis interested ways of doctors, to deprive the world of the advantages of discoveries by suppression, when their promnlgation leads to fame and emolument. In the execution of the work itself, there are many points connected with the origin, progress, and objects of the celebrated doctrine which Mr. Carmichael advocates, that might be made subservient to interesting observation, but within the limits of five pages, scarcely sufficient for that purpose alone, such a task cannot be attempted.

We next come to his work upon Syphilis, upon which his reputation as a medical writer mainly depends. Without entering minutely, for the reasons just stated, into the merits of this publication, it cannot be denied that it has infuenced the treatment of syphilis not only in the country where it was composed, but in others also, by checking the indiscriminate use of mercury, and by directing the professional mind to the $\nabla 2$. riety of sores which had been previously contounded with syphilis. Thongh there are many positions advanced in this work, which admit of great latitude for doubt and speculation, yet if Mr. Car. michael had conferred no other benefit on society than this work, he would well de. serve their gratitude. Besides these works, he has given to the public an essay on mercury, with numerous other detached pieces published in the Journals, and all written with a degree of literary abi. lity and rhetorical tact, which seldom falls to the lot of medical anthors. Something, and only a little, remains to be said of the man, now that we have done with the author, in obedicnce to the Paul Pryism of the age, so curious in this respect. To those persons, however, who have been amused for the last quarter by descriptions of Dr. Parr's wig, his shoebuckles and bon mots, Mr. Carmichael offers little to gratify a propensity for gossip. He is a man of very plain manners, unpretending address, nnostentatious habits, and on every subject of liberal opinions. As a surgical operator, his bold use of the knife would be awful to a spectator unacquainted with his perfect knowledge of what he was doing; and as a lecturer, though I have heard him in that capacity, my recollections on the subject are too indistinct to be redaced to language. He is one of the few surgeons of Dublin whose success has grown out of the fertility of his own mind, unwatered by a rill of lordly patronage. His fame is therefore not the polluted ex. halation of a job, or his fortune the fruit of the forcing-frame. Neither bishop, priest, nor parson, nor any other second. ary minister of Providence on earth, had any thing, that I know of, to do with placing him, as he is at present, on a level with the highest in the profession in Dub. lin. By self-exertion solely, he has worked his way to eminence and independence-the highest praise that can be bestowed on a professional man in Ireland, where so many efforts are made to deprive merit of its rewards. One drawback must be made upon this unqualified approbation. He has not taken that place in the College Cabinet, which his taleuts and, above all, his honesty, qualify him to fill. Why stand by in silenee, while Mr. Todd and his creatures are voting away the establishment to destruction? Does he experience no self-abasement at the prospect of seeing such a man as grinder Harrison appointed to a profes- 
sorship at the retirenent of his brother-inlaw Mr. Colles, who has it in contemplation to inflict this farewell disgrace on the College, when he can pack a court base enough to succumb to his dictation? Does lie think the existence of a law unrepealed on the stamte book of the Corporation, by which law such an abuse could by possibility be committed by any individual, is compatible with the duties which he owes to himself and society? Does he feel no qualms of conscience, no indignation rise within him, at seeing two hundred pounds given to such a man as Mr Henthorne, under pretence of buying plate for him, while the registered pupils, whose money is thus squandered away, are not allowed as much as a book to read? If he do not feel the gorge of honest contempt swell his breast at witnessing such corruption, and come forward to resist it with energy, then, indeed, the estimate just delivered of his character has been conceived in ignorance, and executed by a partial hand.

\section{Erinensis.}

P.S. I have to acknowledge the receipt of a "Sketch of Mr. Harrison," forwarded to me a long time back by the Editor of THE LANCET, and to return the writer my sincere thanks for the perusal of that document, which shall be made use of at a proper time.

Erinexsis.

\section{COPLAND'S MAUSOLEUM.}

The last Number of this publication contains four original papers; the first by George Darling, M.D. on the uses of chlorate of soda in medicine. He says,

"The chlorate of soda was introduced to my notice as a medicine eighteen years ago, by the late Dr. Helenus Scott, when I had the pleasure of becoming acquainted with him in India. He had employed it in secondary syphilis, and in pseudo. syphilitic affections, but in these only. lyy his advice, $I$ gave it at the time in some cases of that description, and with so mnch success, that $I$ resolved to make a full trial of its powers whenever a fa. vourable opportunity occurred. Circum. stances, which it is unnecessary to menticn, deprived me of the opportanity desiled till some years afterwasds, when I entered on practice in London. I began then to administer it internally, in chro- nic diseases of the skin; and in those bilions, or rather dyspeptic disorders, for which pure chlorine was recommended by Dr. Scott. I soon found that it was a vaInable medicine in these complaints, equal, if not superior, to chlorine in its effects, besides having the advantage of being a much more agreeable, as well as a more manageable preparation.

Having satisfied myself of the efficacy of the clilorine as an internal remedy, $\mathbf{I}$ was led to try it as an external application; and my principal object in making this communication, is to draw the attention of the profession to its merits, when used in this manner.

To attempt to particularise all the varieties of cutaneous disease in which $\mathbf{I}$ have prescribed it with advantage, would be inconsistent with the limits of this sketch. For the purpose in view it will suffice to state, that it is well adapted to all those chronic affections of the skin for which stimulating lotions are nsually recommended; and in particular, that in cases of slonghing in the erythema, from local irritation, to which children are particularly liable, in impetiginous, and in pruriginous affections, it has proved successfil in many instances, after the failure of all the remedies in common use.

In affections of the mncons surfaces, which admit of its application, it is still more efficacious than in complaints of the skin. Of its good effects in those of the mouth, of the eyes, and of the vagina, I am enabled to speak from ample experience. Hitherto I have not directed it for the urethra, although disposed to think that it will be found of no small service in the chronic inflammatory disorders to which that organ is especially subject.

It is strikingly beneficial in erythematous inflammation, and in nlcerations of the throat. As a gargle, I have employed it in numerous examples of this description during the last ten years; and I am justified in saying, that it has been rarely used without advantage, and, that when the state of the constitution permitted a cure by local applications, it has never failed to give speedy and complete relief.

Recently I have ascertained, that it is no less effectual in controlling the inflammation of the mouth produced by mercury. Indeed, I know of no remedy at all comparable to it in this very troublesome affection. Applied diligently at the commencement, it seldom fails to arrest the progress of the salivation; and in the worst cases, when the flow of saliva has been excessive, the ulceration extensive, and the pain so severe as to prevent sleep, it has given comparative ease in a 